\title{
An incidental retroperitoneal solitary fibrous tumor
}

\author{
Gianfranco Bassi ${ }^{*}$, Salvador B. Velasquez ${ }^{2}$, Roberto F. Orozco ${ }^{3}$ and Rudolph Garcia-Gallont ${ }^{2}$ \\ *Correspondence: bassi_gianfranco@hotmail.com

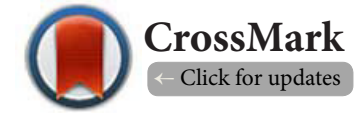 \\ ${ }^{1}$ Herrera Llerandi Hospital, Department of Surgery, Intern, Guatemala. \\ ${ }^{2}$ Herrera Llerandi Hospital, Department of Surgery, Attending Surgeon, Guatemala. \\ ${ }^{3}$ Herrera Llerandi Hospital, Department of Pathology, Guatemala.
}

\begin{abstract}
Solitary fibrous tumors (SFTs), are a group of rare, spindle-cell derived fibrous neoplasms most commonly found in the thoracic (pleural) cavity (80\%). However, it has been described that SFTs can affect a wide range of anatomic sites outside the pleura, including retroperitoneum, meningeal, nasal cavity and others (20\%). Solitary fibrous tumors are usually described in patients between 40 and 70 years of age, and are primarily benign. We present the case of a 27 -year-old male with an incidental finding of a retroperitoneal mass, reported during a routine CT-scan for a pneumonia follow-up, its surgical resection and histopathological findings.
\end{abstract}

Keywords: Solitary fibrous tumor, retroperitoneum, extra-thoracic, incidental

\section{Introduction}

Solitary fibrous tumor (SFT) is an extremely infrequent tumor first reported as a pleural tumor in 1898 [1]. This heterogeneous group of tumors includes both benign (80\%) and malignant neoplasm, with an ongoing debate concerning their cell of origin. SFTs are commonly described in mid aged and elderly people, and no risk factor has been identified [2]. Many SFTs are found as asymptomatic incidental masses, while others are aggressive symptomatic tumors; depending primarily on their size and location. Because of their histological variety and rarity, it is almost impossible to predict the individual clinical behavior, therefore immunohistochemical analysis, is the most important pillar for diagnosis and prognosis of this disease [3]. Hematoxylin -eosin staining alone may not be sufficient and rather makes it difficult to separate this tumor from other spindle-cell tumors, for which CD34 stain has been described as the most important immunohistochemical marker. Enbloc resection of the tumor remains to be the cornerstone of treatment, radiotherapy may be useful as an adjuvant therapy for malignant forms, while no evidence supports the use of chemotherapy [2].

\section{Case report}

A 27-year-old male with no significant previous illness or acute symptoms, was referred to us with the incidental finding of an $8 \times 6 \mathrm{cms}$ retroperitoneal mass reported after a CT-scan performed for pneumonia. Six months before his referral, after the tumor was reported, a percutaneous guided biopsy had been performed, and described as a benign tumor. Expectant observation was decided, and he received no treatment; CT follow-ups were scheduled for every 6 months. Six months later, the first follow-up abdominal CT-scan revealed that the tumor had grown more than $50 \%$ of its original size, for which he was referred to evaluate surgical treatment. The vena cava had already been reduced to a slit-like lumen, and the tumor encompassed the right renal hilium (Figures 1A and 1B). Routine biochemistry, chest radiograph and physical examination were completely normal. Patient was admitted for surgery.

During surgery, a solid, fibrous encapsulated tumor was located in the retroperitoneum, displacing but not invading the duodenum, pancreas, renal hilium and aorta, firmly attached to the pre-vertebral fascia, and compressing the vena cava. Apparently the tumor seemed arise from the paravertebral sympathetic ganglia. It was completely excised after careful detachment from all surrounding tissues, vessels and organs; renal vein and artery were preserved; caval and aortic integrity was accomplished. A second, small inter-caval-aortic nodule was also excised and sent in for histopathology. Macroscopically the main tumor was a white, firm, fibrotic mass that measured $8.5 \times 6 \times 4 \mathrm{cms}$ (Figure 2A). On light microscopy (HES), the tumor was reported as a hypocellular neoplasm, primarily composed of abundant fibrous tissue, with thick abnormal collagen fibers mixed with fusiform cells. No mitotic activity, nuclear pleomorphism, or tumoral necrosis was found (Figure 2B). Immunohistochemically, the neoplasic cells were positive for CD34 and bcl-2 stainings, (Figures 2C and 2D) but negative for $\mathrm{S}$ -100 protein. The final histological diagnosis was a benign solitary fibrous tumor. The second, satellite nodule was also described with the same characteristics. There were no complications in the post-operative period and clinical and CT follow up showed 

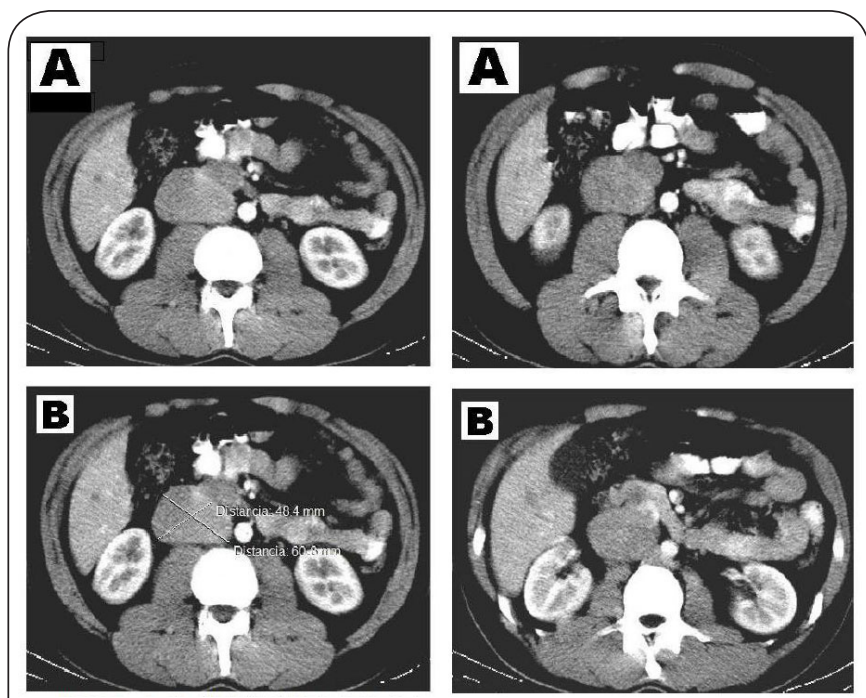

Figure 1. Abdominal CT-scan shows a well encapsulated homogenous, solid, retroperitoneal mass about $5 \times 6 \mathrm{~cm}$ in diameter, compressing the cava and aorta, displacing retroperitoneal structures to the front and left. IV contrast shows no sign of important vascular feeding.

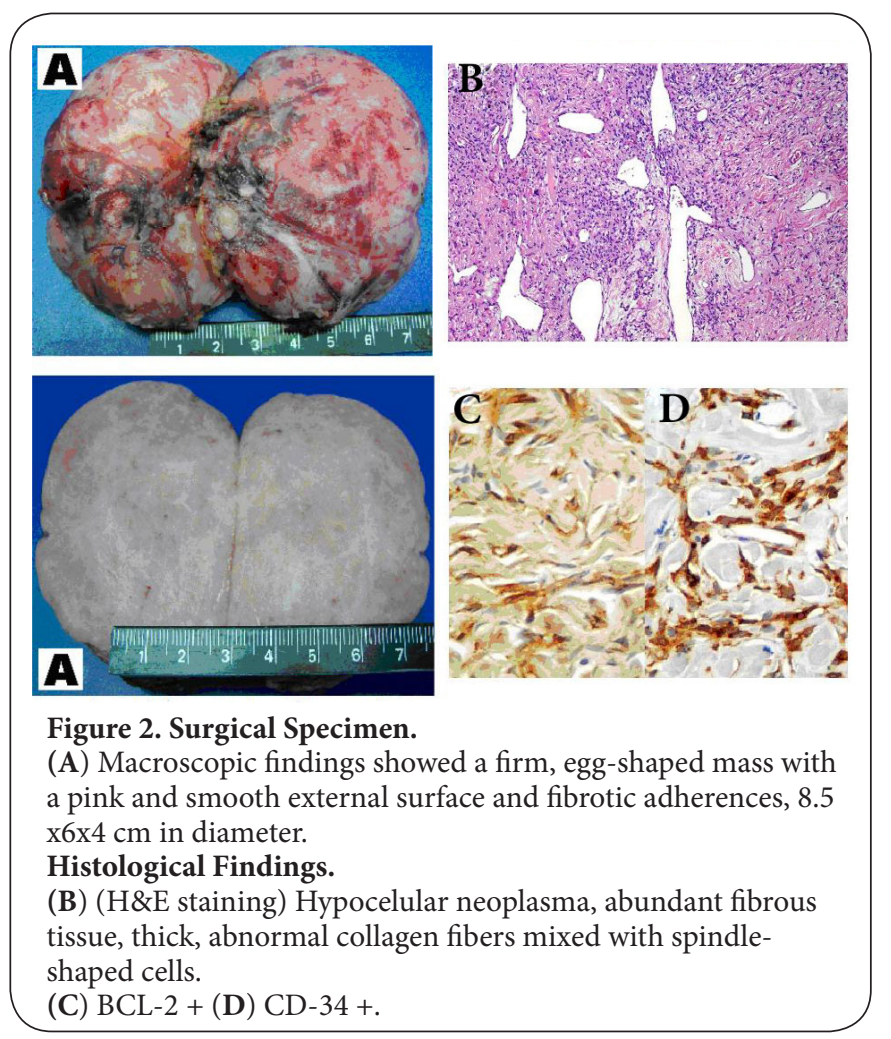

no evidence of recurrence at 6 months after the procedure.

\section{Discussion}

Solitary fibrous tumors, as well as related lesions such as lipomatous hemangiopericytoma or giant cell angiofibroma, are rare fibrous neoplasms originating in the pleura and occurring often in the thoracic cavity, although recent data suggests that as much as $20-30 \%$ of SFTs have extra-pleural origin $[4,5,7]$. Such as the case presented above, a solitary fibrous tumor with retroperitoneal origin, supporting a recent study of Wignal et al., which reviewed 34 cases with histopathologic confirmation of SFT, where only 3 cases (9\%) were intrathoracic [11].

SFTs were initially considered to have mesothelial origin, therefore termed solitary/localized mesotheliomas [6] but its histogenesis has been controversial. Recent histological and immunohistochemical studies define that fibrous tumors of this category have a mesechymal origin as the most probable one $[6,7]$. Because of the unspecific histological morphology of SFTs, (the so-called "patternless pattern") immunohistochemical analysis is vital for the final diagnosis, rather than hematoxylin-eosin staining alone [9].

Immunohistochemical staining has shown that most SFTs are negative for desmin or SL-100, and more than $90 \%$ are positive for $\mathrm{CD} 34$ or $\mathrm{BCL} 2$, making immunoreactivity for these antigens crucial for the final diagnosis of SFTs $[10,11]$.

Solitary fibrous tumors principally affect middle aged adults, with no sex predilection, or other known risk factor $[\mathbf{1 , 5 , 1 2}]$.

Most SFTs are asymptomatic and present as a painless mass, rare and unspecific symptoms may present depending on location, most commonly as a local pressure effect [12].

Because of their variety in presentation, unspecific or null symptoms, SFTs, such as the case presented, are usually diagnosed as an incidental finding in radiographs or CTscans [11].

On imaging studies, SFTs generally appear as a single, lobulated (62\%), well defined mass, with well defined margins (100\%) and occasional collateral feeding vessels (35\%) [11].

Shin et al., reported that SFTs show heterogenous enhancements and areas of different uptake in CT-scans, probably due to the varying cellularity. On T2 MR images, benign SFTs tend to show low signal intensity, whereas malignant SFTs tend to reveal a higher signal intensity on T2-weighted images $[13,14]$.

Encountering a large, solid, vascular tumor, with prominent feeding vessels should always alert the possibility of a solitary fibrous tumor. Percutaneous biopsies offer minimal risk and should be used for diagnosis. SFTs are usually benign (80\%) in all sites, with overall good prognosis with surgical en-bloc resection, which remains to be curative in almost all cases; radiotherapy may be used as adjuvant therapy. Long term follow up is mandatory, with CT-scan or MR imaging $[2,11]$.

\section{Competing interests}

The authors declare that they have no competing interests. 
Bassi et al. Pathology Discovery 2014,

\section{Authors' contributions}

\begin{tabular}{|l|c|c|c|c|}
\hline Authors' contributions & GB & SV & RO & RGG \\
\hline Research concept and design & $\checkmark$ & -- & -- & $\checkmark$ \\
\hline Collection and/or assembly of data & $\checkmark$ & $\checkmark$ & $\checkmark$ & -- \\
\hline Data analysis and interpretation & -- & -- & -- & -- \\
\hline Writing the article & $\checkmark$ & -- & -- & -- \\
\hline Critical revision of the article & -- & -- & $\checkmark$ & -- \\
\hline Final approval of article & -- & -- & -- & -- \\
\hline Statistical analysis & -- & -- & -- & -- \\
\hline
\end{tabular}

\section{Publication history}

Senoir Editor: Takuji Tanaka, Gifu University, Japan.

EIC: Markus H. Frank, Harvard Medical School, USA.

Received: 27-Nov-2013 Revised: 20-Dec-2013

Accepted: 17-Jan-2014 Published: 30-Jan-2014

\section{References}

1. England DM, Hochholzer L and McCarthy MJ. Localized benign and malignant fibrous tumors of the pleura. A clinicopathologic review of 223 cases. Am J Surg Pathol. 1989; 13:640-58. | Article I PubMed

2. Penel N, Amela EY, Decanter G, Robin YM and Marec-Berard P. Solitary fibrous tumors and so-called hemangiopericytoma. Sarcoma. 2012; 2012:690251. | Article | PubMed Abstract | PubMed Full Text

3. Nomura T, Satoh R, Kashima K, Yamasaki M, Hirai K, Satoh F and Mimata $\mathrm{H}$. A case of large solitary fibrous tumor in the retroperitoneum. Clin Med Case Rep. 2009; 2:21-5. I Article I PubMed Abstract I PubMed Full $\underline{\text { Text }}$

4. Goodlad JR and Fletcher CD. Solitary fibrous tumour arising at unusual sites: analysis of a series. Histopathology. 1991; 19:515-22. | Article | PubMed

5. Gold JS, Antonescu CR, Hajdu C, Ferrone CR, Hussain M, Lewis JJ, Brennan MF and Coit DG. Clinicopathologic correlates of solitary fibrous tumors. Cancer. 2002; 94:1057-68. | Article I PubMed

6. Dervan PA, Tobin B and O'Connor M. Solitary (localized) fibrous mesothelioma: evidence against mesothelial cell origin. Histopathology. 1986; 10:867-75. | Article | PubMed

7. Gengler $C$ and Guillou L. Solitary fibrous tumour and haemangiopericytoma: evolution of a concept. Histopathology. 2006; 48:63-74. | Article | PubMed

8. Moran CA, Suster S and Koss MN. The spectrum of histologic growth patterns in benign and malignant fibrous tumors of the pleura. Semin Diagn Pathol. 1992; 9:169-80. I PubMed

9. Westra WH, Gerald WL and Rosai J. Solitary fibrous tumor. Consistent CD34 immunoreactivity and occurrence in the orbit. Am J Surg Pathol. 1994; 18:992-8. | Article I PubMed

10. Takizawa I, Saito T, Kitamura Y, Arai K, Kawaguchi M, Takahashi K and Hara N. Primary solitary fibrous tumor (SFT) in the retroperitoneum. Urol Oncol. 2008; 26:254-9. | Article | PubMed

11. Wignall OJ, Moskovic EC, Thway K and Thomas JM. Solitary fibrous tumors of the soft tissues: review of the imaging and clinical features with histopathologic correlation. AJR Am J Roentgenol. 2010; 195:W5562. | Article | PubMed

12. Enzinger FM, Weiss SW. Solitary fibrous tumor. In: Enzinger FM, Weiss SW, 6th eds Soft tissue tumors. St. Louis, MO: Mosby, 1995; 1021-1031.

13. Shin SS, Jeong YY and Kang HK. Myxoid solitary fibrous tumor of the retroperitoneum: MRI findings with the pathologic correlation. Korean $J$ Radiol. 2008; 9:279-82. | Article I PubMed Abstract | PubMed Full Text

14. Wat SY, Sur M and Dhamanaskar K. Solitary fibrous tumor (SFT) of the pelvis. Clin Imaging. 2008; 32:152-6. I Article I PubMed

\section{Citation:}

Bassi G, Velasquez SB, Orozco RF and Garcia-Gallont R. An incidental retroperitoneal solitary fibrous tumor. Pathol Discov. 2014; 2:1.

http://dx.doi.org/10.7243/2052-7896-2-1 